DOI: https://doi.org/10.47405/mjssh.v5i11.544

\begin{tabular}{|c|c|}
\hline & Malaysian Journal of Social Sciences and Humanities (MJSSH) \\
\hline Malaysian Journal of & Volume 5, Issue 11, November 2020 \\
\hline (MJ-SSH) & e-ISSN : 2504-8562 \\
\hline & $\begin{array}{l}\text { Journal home page: } \\
\text { www.msocialsciences.com }\end{array}$ \\
\hline
\end{tabular}

\title{
Pengaruh Faktor-faktor Tekanan Kerja dalam kalangan Guru di Sekolah Menengah: Satu Analisis Persamaan Struktur (SEM-PLS)
}

\author{
Suhaimi Kamarudin', Muhamad Suhaimi Taat1 \\ ${ }^{1}$ Fakulti Psikologi dan Pendidikan, Universiti Malaysia Sabah (UMS) \\ Correspondence: Suhaimi Kamarudin (mie2421@gmail.com)
}

\begin{abstract}
Abstrak
Kajian yang dijalankan adalah bertujuan untuk menganalisis data beberapa pemboleh ubah eksogen yang diramalkan mempunyai pengaruh terhadap pemboleh ubah endogen (tekanan kerja) dalam kalangan guru. Kaedah penyelidikan kuantitatif melalui analisis Permodelan Persamaan Struktur-Kuasa Dua Terkecil Separa (SEM PLS) digunakan untuk menilai model hipotesis yang menghubungkan kesemua konstruk dengan menggunakan aplikasi Smart PLS versi 3.0. Analisis dalam bentuk model mendapati bahawa kesemua pemboleh ubah eksogen iaitu faktor Tingkah Laku Pelajar, Kekangan Masa dan Beban Tugas mempunyai pengaruh yang signifikan terhadap tekanan kerja. Data utama kajian diperoleh melalui pentadbiran soal selidik kepada 350 orang guru sekolah menengah yang mengajar di Sabah. Permodelan Persamaan Struktur (SEM-PLS) digunakan secara statistik bagi tujuan mengesahkan hipotesis model terakhir Tekanan Kerja. Penyelidikan ini diharapkan dapat mengisi jurang korpus ilmu dan pengetahuan dengan memberi tumpuan kepada sumbangan kuantitatif yang signifikan berkaitan penerokaan faktor-faktor paling dominan terhadap masalah tekanan kerja khususnya dalam kalangan guru. Penemuan kajian ini turut mendedahkan faktor paling berpengaruh terhadap tekanan kerja ialah faktor kekangan masa dengan nilai varians sebanyak 43\%. Selain itu, kajian turut mendapati peranan faktor beban tugas sebagai pemboleh ubah perantara separa antara pemboleh ubah tingkah laku pelajar, dan kekangan masa terhadap tekanan kerja. Implikasi kajian memberi petunjuk bahawa amalan pengurusan masa yang tidak cekap dalam mengurus dan melaksana pelbagai tugas di sekolah jelas memberi kesan negatif terhadap keberkesanan profesionalisme sehingga membawa kepada masalah tekanan kerja. Oleh itu, pengurusan masa secara efektif sewajarnya dapat diamalkan agar segala tanggungjawab yang diberi dapat dilaksanakan dengan sebaik mungkin.
\end{abstract}

Kata kunci: tingkah laku, kekangan masa, beban kerja, tekanan kerja, Structural Equation Modeling Partial Least Square (SEM PLS)

\section{The Influence of Work Stress Factors among Secondary School Teachers: An Analysis of Structural Equations (SEM-PLS)}

\begin{abstract}
The study was conducted to analyze the data of some exogenous variables that are predicted to have an influence on endogenous variables (Work Stress) among teachers. Quantitative research methods through Partial Least Square-Structure Equivalent Model (SEM PLS) analysis were used to evaluate the hypothesis model that connects all constructs using the Smart PLS version 3.0 application. The analysis in the form of a model found that all exogenous variables namely Student Behavior, Time Constraints and Workload factors have a significant influence on work stress. The main data of the
\end{abstract}


study was obtained through the administration of a questionnaire to 350 secondary school teachers who teach in Sabah. Structural Equation Modeling (SEM-PLS) is used statistically for the purpose of validating the final model of Work Stress hypothesis. This research is expected to fill the corpus of knowledge and knowledge gap by focusing on significant quantitative contributions related to the exploration of the most dominant factors on the problem of work stress, especially among teachers. The findings of this study also revealed that the most influential factor in work stress is the time constraint factor with a variance value of $43 \%$. In addition, the study also found the role of the workload factor as a partial intermediate variable between student behavior variables, and time constraints on work stress. The implications of the study indicate that inefficient time management practices in managing and performing various tasks in schools clearly have a negative impact on the effectiveness of professionalism leading to work stress problems. Therefore, effective time management can be practiced so that all the responsibilities given can be implemented as best as possible.

Keywords: behavior, time constraint, workload, work stress, Structural Equation Modeling Partial Least Square (SEM-PLS)

\section{Pengenalan}

Dewasa kini, tekanan di tempat kerja menjadi antara masalah yang serius dalam kalangan guru sehingga berisiko terdedah kepada masalah kesihatan mental dan fizikal, mempengaruhi prestasi dan komitmen kerja selain pengaruh terhadap pencapaian akademik pelajar (Mohamed 2018; Greenberg, Brown, \& Abenavoli, 2016). Tekanan kerja merujuk kepada tindak balas atau ketidakseimbangan tuntutan atau keadaan persekitaran kerja yang dipengaruhi oleh beberapa faktor dalaman atau luaran sehingga mewujudkan rangsangan negatif terhadap tahap kesihatan psikologi dan fisiologi serta tingkah laku individu (Beddu Salam 2014). Kyriacou (2001), mendefinisikan tekanan kerja sebagai suatu pengalaman emosi yang tidak menyenangkan disebabkan oleh beberapa faktor yang dikenal pasti menjadi penyumbang utama kepada masalah yang berlaku, antaranya, faktor persekitaran kerjaya seperti perubahan dalam dasar pendidikan, beban tugas, tingkah laku pelajar yang negatif, tidak berdisiplin dan tahap motivasi yang rendah, kekangan masa, konflik peranan dalam organisasi. Selain itu, Robbins, Coulter dan Woods (2013) mendefinisikan tekanan kerja sebagai reaksi negatif seseorang terhadap tindak balas daripada tuntutan, peluang dan kekangan yang luar biasa di tempat kerja.

Tekanan kerja memberi implikasi negatif kepada tahap kualiti, prestasi dan kepuasan kerja individu sehingga menyebabkan tugas dan tanggungjawab yang diberikan tidak dapat dilaksanakan dengan sebaik mungkin. Menurut Fisher (2011), Kamaruzzaman (2007), senario semasa yang berlaku berkemungkinan menyebabkan warga pendidik tidak dapat memberikan komitmen dan fokus terhadap proses pengajaran dan pembelajaran di dalam kelas seterusnya memberi implikasi terhadap prestasi akademik pelajar dan keseluruhan sistem sosial selain menjadi penghalang kepada agenda merealisasikan visi dan misi Kementerian Pendidikan bagi memenuhi aspirasi pembangunan negara. Hal sedemikian dilihat menjadi suatu ancaman terhadap profesion keguruan yang menjadi peneraju dan peranan utama dalam membina modal insan bagi memacu agenda pembangunan negara pada masa hadapan.

\section{Literatur Kajian}

Literatur penyelidikan membuktikan isu dan masalah berkaitan faktor-faktor penyebab kepada masalah tekanan kerja dalam kalangan guru semakin mendapat perhatian (Ismail 2015; Mohamad Abdillah Royo \& Woo 2010; Byrne, 2013). Penyelidikan dan kajian-kajian lepas menunjukkan bahawa profesion keguruan adalah kerjaya yang paling tinggi berisiko mengalami tekanan kerja berbanding kerjaya lain disebabkan oleh pelbagai faktor persekitaran organisasi (Kidger etal, 2016; Sanyal, Fernandes, \& Fatima, 2016; De Simone, Cicotto, \& Lampis, 2016; Shkembi, Melonashi, \& Fanaj, 2015; Ibrahim Jari, 2014; Tajulashikin, Fazura, \& Ibrahim, 2013). Menurut Sprenger (2011), 100\% 
responden bersetuju bahawa profesion keguruan adalah bidang kerjaya yang sering mengalami tekanan kerja sehingga berisiko menyumbang kepada masalah kesihatan yang serius. Aspek-aspek tersebut akan memberikan kesan terhadap profesionalisme guru termasuklah sikap akademik dan efikasi kendiri mereka (Muhamad Suhaimi \& Gladys, 2014). Apatah lagi, guru pada era ini sering dipertanggungjawabkan dengan pelbagai tugasan khususnya bagi pelaksanaan pengajaran abad ke-21 (Jaggil \& Muhamad Suhaimi, 2018).

Kajian oleh Kinman dan Wray (2014) turut konsisten apabila mendapati $87 \%$ responden bersetuju bahawa profesion pendidikan adalah bidang kerjaya yang seringkali berdepan dengan masalah tekanan kerja yang tinggi disebabkan oleh pelbagai faktor persekitaran kerja. Selain itu, kajian DarlingHammond (2003) dan Ingersoll (2003) mendapati, satu pertiga daripada sebahagian guru di Amerika Syarikat meninggalkan profesion kerana mengalami masalah tekanan kerja yang tinggi disebabkan oleh pelbagai faktor persekitaran. Menurut Kamentz (2015), Shahril (2013), berhadapan dengan masalah melibatkan pelbagai faktor tekanan kerja, akan memberi kesan negatif terhadap tahap kesihatan, kesejahteraan mental, emosi, fizikal, tingkah laku, prestasi, kualiti, produktiviti, seterusnya kesan terhadap kualiti perkhidmatan, prestasi akademik dan pembelajaran pelajar.

Hatta Sidi dan Mohamed Hatta (2002) menyatakan terdapat banyak faktor tekanan kerja sama ada secara langsung atau tidak langsung, melibatkan individu itu sendiri atau melibatkan sekelompok manusia, persekitaran, dan keluarga. Menurut Mathew (2011) dan Gladys dan Muhamad Suhaimi (2015), struktur dan iklim sekolah, persekitaran, hubungan dengan masyarakat dan faktor dalaman pekerjaan antara faktor penyumbang kepada masalah kesihatan fizikal dan mental. Selain itu, beberapa kajian menyatakan bahawa antara punca utama guru mengalami tekanan kerja adalah disebabkan oleh beban tugas dan kesuntukan masa (Abdul Said Ambotang \& Muhamad Hisyam 2014), tingkah laku pelajar dan kekangan masa (Mohd Zuri Ghani dan Ibrahim (2014),tingkah laku pelajar, beban tugas dan kekangan masa (Ooi Chew Hong \& Aziah 2015), beban tugas pentadbiran dan tingkah laku pelajar (Davidson 2009), Pengaruh dan kesan pelbagai faktor persekitaran kerja yang dialami memberi implikasi kepada perubahan dan amalan budaya kerja selain membawa kepada masalah tekanan kerja dan tahap kesihatan diri. Jika dilihat dari aspek psikologi, individu yang kerap mengalami tekanan dalam kehidupan akan sentiasa berada dalam kebimbangan, kemurungan, keresahan, keletihan emosi, fokus tumpuan yang rendah dan tidak dapat mengawal kemarahan apabila berhadapan dengan situasi yang tegang, sehingga berisiko membawa kepada penyakit fizikal dan mental yang serius serta perubahan tingkah laku (Yaribeygi, Panahi, Sahraei, Johnston, \& Sahebkar, 2017; Haryati, 2013), prestasi kerja yang rendah (Brown, Ralph, \& Brember 2002), masalah ketidakhadiran (Naghieh, Montgomery, Bonell, Thompson, \& Aber, 2015).

Kajian-kajian melibatkan beberapa faktor yang paling berpengaruh terhadap masalah tekanan kerja sememangnya telah banyak dibincangkan oleh pengkaji-pengkaji lepas. Menurut Mearsn dan Cain (2003), Azizi Yahaya, Shahrin Hashim (2006). (2008), Kamaruzaman (2007), Chun Cheng dan Amiruddin (2011), Mohd Zuri Ghani, Ahmad, dan Suzana Ibrahim, (2014), Ooi Chew dan Aziah Ismail (2015) faktor pengurusan berkaitan tingkah laku pelajar melibatkan aspek disiplin dan masalah pembelajaran mempunyai pengaruh paling dominan terhadap masalah tekanan kerja. Selain itu, Karaj dan Rapti (2012), Schaubman, Stetson dan Plog (2011), Abdul Said Ambotang, Norazizah Pilus dan Andin (2014), masalah berkaitan tingkah laku pelajar antara faktor utama kepada kewujudan masalah tekanan kerja guru selain menyumbang kepada nilai korelasi yang tinggi. Menurut Aldrup, Klusmann, Ludtke, Gollner, \& Trautwein, (2018) tingkah laku pelajar melibatkan gangguan di dalam kelas dan masalah disiplin sering dikaitkan dengan kesejahteraan dan masalah tekanan kerja guru. Seterusnya, menurut Chua (2004), Lemairie (2009), Davidson (2009), Kaur, (2011), Sugden (2010), De Simone et.al (2016), faktor beban tugas yang tinggi merupakan faktor paling berpengaruh terhadap masalah tekanan kerja dalam kalangan guru. Selain itu, kajian Skaalvik dan Skaalvik (2011), Raja Maria (2011), Muhamad Abdillah Royo dan Woo (2010) Kokkinos (2007), Hakanen, Bakker, dan Schaufeli, (2006) pula berbeza dapatan apabila mendapati faktor kekangan masa melaksanakan aktiviti pengajaran dan pembelajaran, menyelesaikan pelbagai tugas dan waktu rehat yang terhad menjadi faktor paling utama terhadap masalah tekanan kerja. Kajian oleh Chan et.al (2010) mendapati masalah berkaitan tekanan kerja meningkat sebanyak $97.3 \%$ dalam tempoh 5 tahun disebabkan oleh faktor beban kerja yang tinggi, tekanan masa, mengurus tingkah laku dan pembelajaran pelajar di sekolah. 


\section{Objektif Kajian}

Kajian berkaitan faktor-faktor penyumbang kepada masalah tekanan kerja dalam kalangan guru sememangnya telah banyak dilakukan secara umum. Namun kajian berfokus kepada penyelidikan dan penerokaan terhadap faktor tingkah laku pelajar, kekangan masa dan beban tugas masih kurang dijalankan. Justeru, kajian yang dijalankan adalah bertujuan untuk melihat persepsi guru berkaitan tahap faktor-faktor tekanan kerja yang dikemukakan selain melihat sejauh mana pemboleh ubah eksogen mempengaruhi pemboleh ubah endogen dalam kalangan guru di Sabah.

\section{Metodologi Kajian}

Bagi mencapai tujuan penyelidikan, reka bentuk bukan eksperimen (non experimental) telah dipilih dalam kajian ini kerana penggunaannya adalah lebih praktikal apabila melibatkan responden yang ramai dan kutipan data dapat dilakukan dalam tempoh masa yang singkat. Seramai 350 orang guru dari 10 buah sekolah di kawasan bandar dan luar bandar terlibat sebagai subjek kajian. Subjek kajian terdiri daripada guru-guru di sepuluh buah sekolah menengah di negeri Sabah yang mengajar di kawasan bandar dan luar bandar. Kajian ini terbahagi kepada empat bahagian yang melibatkan pengumpulan set-set data. Bahagian A ialah maklumat Demografi iaitu maklumat demografi seperti jantina, dan lokasi sekolah. Bahagian B ialah skala yang mengandungi 12 item bagi mengukur persepsi Tingkah Laku Pelajar di sekolah. Skala item Bahagian $\mathrm{C}$ bagi faktor kekangan masa juga diukur dengan skala Likert 5 mata iaitu dari sangat tidak setuju kepada sangat setuju. Bahagian D pula ialah skala mengandungi 13 item bagi mengukur persepsi guru berkaitan faktor Beban Tugas di sekolah. Data yang diperoleh telah dianalisis dengan menggunakan perisian SPSS versi 22.0. Ujian statistik deskriptif yang merangkumi kekerapan, peratusan dan min telah digunakan untuk memerihalkan profil demografi dan tahap faktor-faktor tekanan kerja. Sementara analisis SEM dengan menggunakan aplikasi SmartPLS digunakan untuk melihat pengaruh faktor tingkah laku pelajar, kekangan masa dan beban tugas terhadap tekanan kerja.

\section{Prosedur Analisis Data}

Analisis data dalam penyelidikan adalah dengan menggunakan sistem perisian statistik IBM SPSS versi 22 dan SmartPLS 3.0. Analisis statistik deskriptif digunakan bagi tujuan menentukan profil demografi responden melibatkan jantina guru, selain menentukan tahap pemboleh ubah menggunakan nilai skor min. Analisis kovarians PLS-SEM pula diaplikasi bagi menentukan pengaruh antara pemboleh ubah eksogen dan pemboleh ubah endogen.

\section{Instrumen}

Instrumen yang digunakan adalah berbentuk borang soal selidik tertutup yang dibangunkan oleh Boyle et.al (1995) dan Fimian J.(1988). Instrumen Teacher Stress Inventory (TSI) yang digunakan sememangnya telah diubah suai berdasarkan keperluan kepada fokus penyelidikan semasa oleh Ibrahim Jari (2014), Mokhtar (1998) dan Anis Salwa Abdullah dan Siti Noor Ismail (2019) bagi tujuan menjelaskan dimensi dan persepsi berkaitan faktor yang dikemukakan iaitu faktor tingkah laku pelajar, kekangan masa dan beban tugas. Instrumen kajian ini terbahagi kepada lima bahagian yang melibatkan pengumpulan set-set data. Bahagian A ialah maklumat Demografi iaitu maklumat demografi seperti jantina, dan lokasi sekolah. Bahagian B ialah skala yang mengandungi 12 item bagi mengukur persepsi Tingkah Laku Pelajar di sekolah. Skala item Bahagian C bagi faktor kekangan masa juga diukur dengan skala Likert 5 mata iaitu dari sangat tidak setuju kepada sangat setuju. Bahagian D pula ialah skala mengandungi 13 item bagi mengukur persepsi guru berkaitan faktor Beban Tugas di sekolah, manakala bahagian E melibatkan skala item bagi mengukur tahap tekanan kerja berdasarkan aspek fizikal, psikologikal, tingkah laku dan minda. 


\section{Hasil Kajian}

\section{Profil Responden}

Jadual 1 menunjukkan jumlah bilangan responden yang terlibat dalam kajian ini terdiri daripada guru lelaki seramai 105 (30\%) dan guru perempuan seramai 245 orang (70\%).

Jadual 1: Profil Sampel Kajian

\begin{tabular}{lll}
\hline Profil Responden Jantina & Bilangan & Peratusan \\
\hline Lelaki & 105 & $30 \%$ \\
Perempuan & 245 & $70 \%$ \\
\hline
\end{tabular}

Jadual 2 menunjukkan jumlah bilangan responden berdasarkan lokasi sekolah. Daripada 350 orang responden yang terlibat, seramai 190 orang $(54.3 \%)$ adalah mewakili kawasan bandar dan $160(45.7 \%)$ pula mewakili sekolah dari kawasan luar bandar.

Jadual 2: Profil Lokasi Kajian

\begin{tabular}{lll}
\hline Profil Lokasi & Bilangan & Peratusan \\
\hline Bandar & 190 & $54.3 \%$ \\
Luar Bandar & 160 & $45.7 \%$ \\
\hline
\end{tabular}

\section{Analisis Kesahan dan Kebolehpercayaan}

Jadual 3 menunjukkan analisis kesahan dan kebolehpercayaan konstruk. Item-item bagi setiap konstruk telah mencapai piawaian analisis kesahan dan kebolehan yang telah ditetapkan iaitu melebihi 0.7 (Fornell \& Larcker, 1981, Gefen \& Straub, 2008, Hair et.al 2010). Seterusnya, bagi nilai kebolehpercayaan komposit, skala pengukuran mempunyai ketekalan dalaman yang tinggi apabila nilai yang diperoleh adalah sekurang-kurangnya 0.7 (Hair et.al 2017, Sekaran \& Bougie 2010). Di samping itu, skor purata varians yang diekstrak (AVE) pula melebihi nilai 0.5 bagi mengesahkan nilai konvergen yang diperoleh adalah tinggi. Analisis ini memberi petunjuk bahawa konstruk-konstruk kajian telah memenuhi piawaian kesahan berdasarkan standard yang telah ditetapkan (Hair et.al 2017).

Jadual 3: Nilai Cronbach Alpha, Composit Realibility (CR) dan Average Variance Extracted (AVE)

\begin{tabular}{lllll}
\hline Konstruk/ Faktor & $\begin{array}{l}\text { Muatan } \\
\text { Faktor }\end{array}$ & $\begin{array}{l}\text { CA } \\
(>\mathbf{0 . 0 7})\end{array}$ & $\begin{array}{l}\text { CR } \\
(>\mathbf{0 . 0 7})\end{array}$ & $\begin{array}{l}\text { AVE } \\
(>\mathbf{0 . 0 5})\end{array}$ \\
\hline Tingkah Laku Pelajar & $0.56-0.82$ & 0.86 & 0.90 & 0.55 \\
Kekangan Masa & $0.76-0.81$ & 0.87 & 0.90 & 0.61 \\
Beban Tugas & $0.75-0.87$ & 0.96 & 0.96 & 0.65 \\
\hline
\end{tabular}

\section{Analisis Kesahan Diskriminan}

Analisis jadual 4 menunjukkan keputusan ujian kesahan diskriminan menggunakan kaedah Fornell Lacker (1981) bagi setiap konstruk. Seperti yang dibincangkan, kesahan diskriminan berlaku apabila nilai punca kuasa dua adalah lebih besar daripada elemen bukan pepenjuru bagi setiap kolum dan lajur. Ini menunjukkan bahawa pembinaan konstruk mempunyai hubungan yang kuat dengan indikator yang diwakili, berbanding dengan konstruk yang tidak diwakili (Hair et.al 2017). Dapatan analisis menunjukkan bahawa nilai pemboleh ubah lanten atau konstruk mempunyai nilai lebih besar daripada nilai korelasi antara pemboleh ubah yang lain, Ini mengesahkan bahawa instrumen kajian memenuhi kriteria kesahan diskriminan. 
DOI: https://doi.org/10.47405/mjssh.v5i11.544

Jadual 4: Analisis Fornell Lacker

\begin{tabular}{lllll}
\hline Konstruk / Faktor & $\mathbf{x 1}$ & $\mathbf{x 2}$ & $\mathbf{x 3}$ & \\
\hline Tingkah Laku Pelajar x1 & 0.74 & & & \\
Kekangan Masa x2 & 0.40 & 0.78 & 0.81 \\
Beban Tugas x3 & 0.38 & 0.73 & \\
\hline
\end{tabular}

\section{Analisis Cross Loading}

Analisis cross loading merupakan salah satu cara untuk mengesahkan Kesahan Diskriminan untuk setiap konstruk di dalam model. Menurut Hair et.all (2014) loading setiap item mestilah lebih tinggi daripada faktor yang diwakili dan rendah pada faktor yang tidak diwakili. Keputusan analisis di bawah menunjukkan item-item mempunyai loading yang tinggi pada faktor yang diwakili, walau bagaimanapun item tersebut mempunyai loading yang rendah pada item yang tidak di wakili.

Jadual 5: Analisis Cross Loading

\begin{tabular}{llll}
\hline Faktor & $\begin{array}{l}\text { Tingkah Laku } \\
\text { Pelajar }\end{array}$ & Kekangan Masa & Beban Tugas \\
\hline Tingkah Laku Pelajar 14 & $\mathbf{0 . 7 4}$ & 0.36 & 0.24 \\
Tingkah Laku Pelajar 15 & $\mathbf{0 . 7 5}$ & 0.34 & 0.18 \\
Tingkah Laku Pelajar 16 & $\mathbf{0 . 7 6}$ & 0.33 & 0.23 \\
Tingkah Laku Pelajar 17 & $\mathbf{0 . 7 9}$ & 0.38 & 0.27 \\
Tingkah Laku Pelajar 18 & $\mathbf{0 . 8 2}$ & 0.38 & 0.18 \\
Tingkah Laku Pelajar 19 & $\mathbf{0 . 7 7}$ & 0.33 & 0.19 \\
Tingkah Laku Pelajar 20 & $\mathbf{0 . 5 6}$ & 0.32 & 0.26 \\
Kekangan Masa 28 & 0.36 & $\mathbf{0 . 7 6}$ & 0.36 \\
Kekangan Masa 29 & 0.37 & $\mathbf{0 . 8 1}$ & 0.37 \\
Kekangan Masa 30 & 0.37 & $\mathbf{0 . 7 6}$ & 0.37 \\
Kekangan Masa 31 & 0.28 & $\mathbf{0 . 7 8}$ & 0.28 \\
Kekangan Masa 32 & 0.33 & $\mathbf{0 . 8}$ & 0.33 \\
Kekangan Masa 33 & 0.36 & $\mathbf{0 . 7 8}$ & 0.36 \\
Kekangan Masa 34 & 0.36 & $\mathbf{0 . 7 6}$ & 0.36 \\
Kekangan Masa 35 & 0.37 & $\mathbf{0 . 8 1}$ & 0.37 \\
Beban Tugas 1 & 0.78 & 0.42 & $\mathbf{0 . 7 8}$ \\
Beban Tugas 10 & 0.80 & 0.29 & $\mathbf{0 . 8 0}$ \\
Beban Tugas 11 & 0.82 & 0.27 & $\mathbf{0 . 8 2}$ \\
Beban Tugas 12 & 0.84 & 0.37 & $\mathbf{0 . 8 4}$ \\
Beban Tugas 13 & 0.77 & 0.32 & $\mathbf{0 . 7 7}$ \\
Beban Tugas 2 & 0.79 & 0.41 & $\mathbf{0 . 7 9}$ \\
Beban Tugas 3 & 0.81 & 0.42 & $\mathbf{0 . 8 1}$ \\
Beban Tugas 4 & 0.87 & 0.42 & $\mathbf{0 . 8 6}$ \\
Beban Tugas 5 & 0.86 & 0.43 & $\mathbf{0 . 7 7}$ \\
Beban Tugas 6 & 0.77 & 0.31 & $\mathbf{0 . 7 5}$ \\
Beban Tugas 7 & 0.75 & 0.25 & $\mathbf{0 . 7 7}$ \\
Beban Tugas 8 & 0.83 & 0.39 & 0.24 \\
Beban Tugas 9 & 0.77 & &
\end{tabular}

Dalam kajian yang dijalankan, pemboleh ubah beban tugas juga diklasifikasikan sebagai pemboleh ubah perantara separa antara hubungan pemboleh ubah endogen iaitu faktor tingkah laku pelajar dan kekangan masa terhadap tekanan kerja berdasarkan teori yang telah dirumuskan oleh Kenny dan Baron (1986). Berhadapan dengan pelbagai tugas dan tanggungjawab yang perlu dilaksanakan melibatkan pengurusan pelajar seperti mengawal tingkah laku dan disiplin, menjaga dan mengawal keselamatan pelajar, sehingga menyebabkan guru berdepan dengan masalah kekangan masa untuk menyelesaikan pelbagai perkara lain seterusnya menyebabkan guru mengalami masalah tekanan kerja di sekolah (Butt 
\& Lance, 2005). Dapatan ini turut selari dengan Van Bogaert et al. (2014), beban tugas berperanan sebagai mediator melibatkan pengaruh faktor persekitaran kerja terhadap masalah berkaitan tekanan atau burnout dalam kalangan individu.

\section{Dapatan Kajian}

Dapatan kajian analisis deskriptif menunjukkan bahawa persepsi guru berkaitan tahap faktor tingkah laku pelajar berada pada tahap yang sederhana dengan nilai min sebanyak 3.18. Hasil dapatan kajian yang diperoleh adalah konsisten dengan kajian yang dijalankan oleh Aldrup et.al (2018) dan Samad, Hashim, Moin, \& Abdullah (2011). Bagi faktor beban tugas, nilai min yang diperoleh adalah tinggi dengan nilai sebanyak 3.80. Dapatan kajian turut selari dengan Mohd Arshad dan Mustapha (2017), Norashid dan Hamzah (2014), dan Skaalvik dan Skaalvik (2016). Seterusnya, bagi faktor kekangan masa, nilai min adalah sebanyak 3.34 berada pada tahap yang sederhana. Dapatan ini turut selari dengan Mohd Zuri Ghani et.al (2014), Ooi Chew Hong dan Aziah Ismail (2015) faktor kekangan masa yang dialami berada pada tahap yang sederhana. Bagi analisis kajian berdasarkan laluan koefisien, pengaruh faktor Tingkah Laku Pelajar $(\beta=0.18, \mathrm{p}<0.05)$ terhadap tekanan kerja menunjukkan hubungan yang positif dan signifikan. Oleh itu, hasil kajian ini menyokong dapatan kajian lepas (Karaj \& Rapti 2013, Geving 2007, Collie, Shipka \& Perry 2012; Grayson \& Alvarez 2008) yang membuktikan bahawa hubungan antara faktor tingkah laku pelajar terhadap tekanan kerja adalah positif dan signifikan. Dalam konteks persekitaran sekolah, pengalaman guru berhadapan dengan pelbagai tingkah laku dan karenah pelajar yang negatif seperti masalah disiplin, motivasi yang rendah terhadap akademik dan pembelajaran sememangnya mempengaruhi kepada kewujudan masalah tekanan kerja sehingga memberi kesan kepada tahap kesihatan dan kesejahteraan mental dan fizikal guru (Hopkins 2014).

Seterusnya, pengaruh faktor Kekangan Masa $(\beta=0.43, \mathrm{p}<0.05)$ turut menunjukkan hubungan yang positif dan signifikan. Hasil kajian yang diperoleh turut menyokong dapatan kajian lepas (Karaj \& Rapti 2013, Kyriacou 2001, Thomas Clarke \& Lavery 2003, Kokinos, 2007, Zedan, 2012) yang turut membuktikan bahawa hubungan faktor kekangan masa terhadap tekanan kerja dalam kalangan guru adalah positif dan signifikan. Kekangan masa dalam konteks pendidikan merujuk kepada batasan waktu atau keperluan melakukan pelbagai tugas atau tanggungjawab dalam waktu yang terhad di sekolah seterusnya terpaksa menyambung tugas-tugas yang diberi di luar waktu persekolahan seperti menyelesaikan masalah disiplin pelajar dan masa rehat yang terhad. Keadaan yang berlaku boleh menyebabkan risiko kepada masalah kesihatan yang serius dan simptom keletihan yang berpanjangan (Bollsard, Cartron \& Gollac 2003). Seterusnya, dapatan analisis turut menunjukkan bahawa pemboleh ubah eksogen iaitu faktor beban tugas turut berperanan secara signifikan dalam mempengaruhi tekanan kerja dalam kalangan guru di Sabah. Penglibatan pengaruh beban tugas $(B=0.17, p<0.05)$ menunjukkan hubungan yang positif dan signifikan. Oleh itu, hasil kajian ini turut menyokong dapatan kajian-kajian lepas (Kokoroka \& Sanda 2019; De Simone 2017; Karaj \& Rapti 2013; Nwankwo, 2013; Klassen \& Chiu, 2010; Helen et.al 2005; Ingvarson, 2005) yang turut konsisten membuktikan bahawa hubungan faktor beban tugas terhadap tekanan kerja guru adalah positif dan signifikan. Dalam konteks kajian ini, analisis mendapati, pengaruh faktor beban tugas berada pada tahap yang rendah dalam mempengaruhi tekanan kerja dalam kalangan guru.

Analisis Jadual 6 menjelaskan bahawa pemboleh ubah Tingkah Laku Pelajar dan indikatornya mempunyai pengaruh yang signifikan terhadap pemboleh ubah endogenus iaitu Tekanan Kerja $(\beta$ $=0.18, t=3.33, p<0.05$ ).

Jadual 6: Analisis PLS Pengaruh Tingkah Laku Pelajar Terhadap Tekanan Kerja

\begin{tabular}{lllll}
\hline Pemboleh ubah & $\begin{array}{l}\text { Pekali } \\
\text { Lintasan }\end{array}$ & $\boldsymbol{t}$ & Nilai $\boldsymbol{p}$ & Keputusan \\
\hline $\begin{array}{l}\text { Tingkah laku Pelajar-> Tekanan } \\
\text { Kerja }\end{array}$ & 0.18 & 3.33 & 0.00 & $\begin{array}{l}\text { Positif dan } \\
\text { Signifikan }\end{array}$ \\
\hline
\end{tabular}

*Signifikan pada aras $t>1.96$ dan $p<0.05$ 
Hipotesis $\mathrm{Nul}\left(\mathrm{Ho}^{1}\right)$ : Tidak terdapat pengaruh yang signifikan di antara Faktor Tingkah laku pelajar terhadap Tekanan Kerja dalam kalangan guru. Keputusan ujian yang dilakukan terhadap sampel $(\mathrm{N}=350)$ adalah signifikan $(\beta=0.18, t=3.33, p<0.05)$. Oleh yang demikian, hipotesis $\mathrm{Nul}\left(\mathrm{Ho}^{1}\right)$ adalah ditolak. Dapatan kajian menunjukkan terdapat pengaruh yang signifikan faktor Kekangan Masa terhadap Tekanan kerja dalam kalangan guru.

Analisis Jadual 7 menjelaskan bahawa pemboleh ubah Kekangan Masa dan indikatornya mempunyai pengaruh yang signifikan terhadap pemboleh ubah endogenus iaitu Tekanan Kerja $(\beta=0.43, t=8.55$, $p<0.05)$.

Jadual 7: Analisis PLS Pengaruh Faktor Kekangan Masa Terhadap Tekanan Kerja Guru

\begin{tabular}{lllll}
\hline Pemboleh ubah & $\begin{array}{l}\text { Pekali } \\
\text { Lintasan }\end{array}$ & $\boldsymbol{t}$ & Nilai $\boldsymbol{p}$ & Keputusan \\
\hline Kekangan Masa-> Tekanan Kerja & 0.43 & 8.55 & 0.00 & $\begin{array}{l}\text { Positif dan } \\
\text { Signifikan }\end{array}$ \\
\hline
\end{tabular}

*Signifikan pada aras $t>1.96$ dan $p<0.05$

Hipotesis $\mathrm{Nul}\left(\mathrm{Ho}^{2}\right)$ : Tidak terdapat pengaruh yang signifikan Faktor Kekangan Masa terhadap Tekanan Kerja. Keputusan ujian yang dilakukan terhadap sampel $(\mathrm{N}=350)$ adalah signifikan $(\beta=0.43$, $t=8.55, p<0.05)$. Oleh yang demikian, hipotesis $\mathrm{Nul}\left(\mathrm{Ho}^{2}\right)$ juga adalah ditolak. Dapatan kajian menunjukkan terdapat pengaruh yang signifikan faktor Kekangan Masa terhadap Tekanan kerja dalam kalangan guru.

Analisis seterusnya menjelaskan bahawa pemboleh ubah faktor Beban Tugas dan indikatornya mempunyai pengaruh yang signifikan terhadap pemboleh ubah endogenus iaitu Tekanan Kerja ( $\beta$ $=0.17, t=4.10, p<0.05)$.

Jadual 8: Analisis PLS Pengaruh Beban Tugas Terhadap Tekanan Kerja

\begin{tabular}{lllll}
\hline Pemboleh ubah & $\begin{array}{l}\text { Pekali } \\
\text { Lintasan }\end{array}$ & t-statistik & Nilai $\boldsymbol{p}$ & Keputusan \\
\hline Beban Tugas-> Tekanan Kerja & 0.17 & 4.10 & 0.00 & $\begin{array}{l}\text { Positif dan } \\
\text { Signifikan }\end{array}$ \\
\hline
\end{tabular}

$* \overline{\text { Signifikan pada aras } t>1.96 \text { dan } p<0.05}$

Hipotesis $\mathrm{Nul}\left(\mathrm{Ho}^{3}\right)$ : Tidak terdapat pengaruh yang signifikan Faktor Beban Tugas dengan Tekanan Kerja. Keputusan analisis ujian yang dilakukan adalah signifikan $(\beta=0.17, t=4.10, p<0.05)$. Oleh itu, Hipotesis $\mathrm{Nul}\left(\mathrm{Ho}^{3}\right)$ ditolak. Kesimpulannya, kajian menunjukkan terdapat pengaruh yang signifikan antara pemboleh ubah eksogen (Beban Tugas) dengan pemboleh ubah endogen (Tekanan Kerja).

Rajah 1: Model Hipotesis Tekanan Kerja

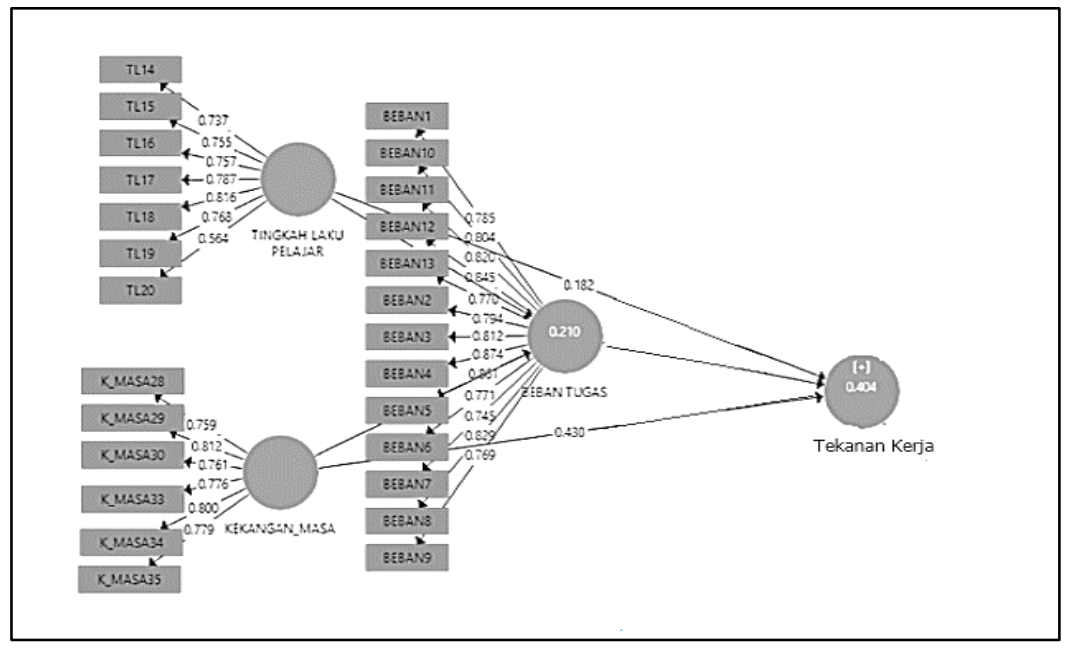




\section{Perbincangan}

Melalui analisis yang telah dijalankan, dapatan kajian menunjukkan bahawa faktor tingkah laku pelajar, kekangan masa dan beban tugas bertindak sebagai pemboleh ubah peramal kepada pemboleh ubah tekanan kerja. Perbincangan turut melibatkan pembinaan model hipotesis terhadap penerokaan dan pengetahuan berkaitan faktor-faktor penyumbang kepada tekanan kerja dalam kalangan guru. Bagi model psikologi yang telah dibangunkan ini, nilai koefisien ketiga-tiga laluan berada pada nilai rendah dan sederhana antara pemboleh ubah eksogen terhadap pemboleh ubah endogen iaitu tekanan kerja menunjukkan nilai iaitu 0.18 bagi tingkah laku pelajar, 0.17 bagi faktor beban tugas dan 0.43 bagi faktor kekangan masa. Dapatan kajian menunjukkan bahawa faktor kekangan masa merupakan faktor peramal yang mempunyai nilai koefisien laluan paling tinggi terhadap tekanan kerja dalam kalangan guru. Dapatan ini memberi petunjuk bahawa faktor kekangan masa yang di alami oleh warga pendidik mempunyai hubungan dan pengaruh yang besar terhadap tekanan kerja dalam kalangan guru di Sabah.

Model kajian yang telah dibina memberi petunjuk kepada kejayaan mencapai suatu keputusan penerokaan yang signifikan dengan peramal-peramal faktor tekanan kerja menjelaskan nilai varians $\mathrm{R}^{2}$ bagi mengukur sejauh mana pemboleh ubah eksogen mempengaruhi pemboleh ubah endogen. Hasil dapatan analisis memberi petunjuk bahawa faktor tingkah laku pelajar, kekangan masa dan beban tugas, masing-masing mempengaruhi pemboleh ubah bersandar (endogenous) iaitu Tekanan Kerja dengan nilai varians sebanyak $40 \%$ pada tahap sederhana, manakala faktor tingkah laku pelajar dan kekangan masa mempengaruhi pemboleh ubah Beban Tugas dengan nilai varians 21 peratus. Menurut Onditi (2013), hasil penyelidikan yang melibatkan psikologi individu, nilai $\mathrm{R}^{2}$ secara kebiasaannya adalah konsisten apabila berada antara nilai $20 \%$ kerana gelagat individu merupakan sesuatu yang sukar dinilai dan diramal berbanding sesuatu yang berkaitan ciri fizikal.

Berdasarkan analisis dalam pembinaan model yang dilakukan, nilai $\mathrm{Q}^{2}$, model dianggap mempunyai kesahan ramalan apabila nilai yang diperoleh adalah lebih besar daripada 0 (Henseler et.al 2014). Oleh itu berdasarkan kriteria daripada Fornell dan Cha (1994) keputusan kajian menunjukkan model yang dibangunkan adalah relevan dan seterusnya menyokong ketepatan ramalan model yang dibangunkan. Dengan merujuk kepada Rajah 1 model turut memberi implikasi teori dan praktikal terhadap permasalahan persekitaran organisasi melalui perkembangan model-model tekanan kerja dengan menggabung jalin beberapa teori tekanan yang secara konsisten dapat membangunkan Model Tekanan Kerja yang lebih berimpak tinggi terhadap bidang kajian pada masa hadapan. Selain itu, model kajian juga mampu memberi sumbangan secara praktikal apabila memberi gambaran secara lebih konsisten bahawa kesemua faktor peramal yang dinyatakan adalah signifikan menyumbang dan mempengaruhi kepada masalah tekanan kerja dalam kalangan guru dengan turut membuktikan bahawa faktor kekangan masa adalah pemboleh ubah paling dominan terhadap masalah tekanan kerja dalam kalangan guru terutama di negeri Sabah. Secara keseluruhannya, Model Faktor Tekanan Kerja yang diilustrasikan secara hipotesis adalah boleh disandari dan mempunyai kesahan dan standard piawaian untuk di aplikasi dalam wacana perbincangan berkaitan faktor-faktor pemboleh ubah eksogen yang mempunyai hubungan dengan pemboleh ubah endogen iaitu tekanan kerja kerana telah memenuhi syarat kebolehpercayaan dan kesahan selain menyokong ketepatan model laluan SmartPLS yang digunakan dalam kajian ini.

\section{Kesimpulan}

Pemodelan Persamaan Struktural (Structural Equation Modeling) atau SEM adalah antara cabang teknik analisis multivariat yang menggabungkan analisis faktor dan regresi, yang membolehkan pengkaji menentukan hubungan atau pengaruh antara item dengan konstruk pemboleh ubah sama ada eksogen mahupun pemboleh ubah endogen, selain melibatkan pengaplikasian kaedah statistik untuk menganalisis lebih banyak pemboleh ubah secara serentak. Pengukuran pemboleh ubah mewakili pengukuran bagi individu, organisasi, peristiwa, aktiviti, situasi dan lain-lain biasanya diperoleh daripada data primer (tinjauan atau pemerhatian) tetapi boleh juga didapati daripada data sekunder. Oleh itu, pembinaan Model Faktor Tekanan Kerja begitu sesuai dengan pendekatan Partial Least Squares Structural Equation Modeling (PLS-SEM) sebagaimana saranan oleh Hair et.al (2017) 
terutama bagi kajian pada masa hadapan. Kajian penyelidikan sebegini sememangnya relevan dengan senario pendidikan semasa untuk dijadikan sumbangan rujukan dan panduan pembinaan model yang berkaitan dengan pelbagai faktor tekanan kerja yang sememangnya wujud dalam persekitaran kerja terutama melibatkan warga pendidik sama ada di sekolah mahupun di institusi pendidikan. Justeru seluruh warga pendidik perlu berganding bahu menyumbang secara lebih proaktif dan berkesan dalam melakukan penerokaan terhadap faktor penyumbang kepada tekanan kerja yang dialami seterusnya merancang pelbagai program intervensi bagi menangani masalah yang berlaku. Menurut Greenberg, Brown dan Abenavoli (2016), beberapa intervensi bagi membantu menangani masalah tekanan kerja dalam kalangan guru antaranya intervensi penglibatan antara kumpulan organisasi bagi membantu budaya kerja dalam organisasi, intervensi antara organisasi dengan individu bagi membina hubungan di tempat kerja, seterusnya intervensi hubungan dalam kalangan guru bagi membantu menyelesaikan permasalahan tekanan kerja yang dialami. Menurut Ngui dan Lay (2015), kecekapan dan kesejahteraan diri memainkan peranan penting dalam membantu mengawal dan menangani daya tahan terhadap faktor tekanan kerja yang dialami, seterusnya Ouellette et.al (2018), iklim organisasi dan hubungan erat serta kolaborasi antara rakan sekerja berpotensi menyediakan persekitaran dan kepuasan kerja yang baik. Justeru pelbagai pihak perlu bekerjasama mencari solusi dan kaedah terbaik menangani masalah berkaitan pelbagai faktor tekanan serta segala macam cabaran bagi meneruskan agenda pendidikan negara demi merealisasikan matlamat kepada sistem pendidikan bertaraf dunia.

\section{Rujukan}

Abdul Said Ambotang, \& Muhamad Hisyam Mohd Hashim. (2011). Hubungan Iklim Kerja dan Stres dalam Pengurusan Bilik Darjah dalam Kalangan Guru Prasekolah The Relation of Work Environment and Stress in Classroom Management among Preschool Teachers. Journal of Techno-Social.

Aldrup, K., Klusmann, U., Ludtke, O., Gollner, R. \& Trautwein, U. (2018). Student misbehavior and teacher well-being: Testing the mediating role of the teacher-student relationship. Learning and Instruction, 58, 126-136. https://doi.org/10.1016/j.learninstruc.2018.05.006

Azizi Haji Yahaya, Shahrin Hashim, T. S. (2006). Occupational stress Among Technical teachers In Technical School in Johore, Malacca and Negeri Sembilan. Journal of Chemical Information and Modeling. https://doi.org/10.1017/CBO9781107415324.004

Beddu Salam Baco (2014). Modal Psikologi (Psychological Capital), stres kerja dan komitmen kerja (work engagement): Satu penelitian awal. Seminar Kebangsaan Integriti Keluarga 2014. https://doi.org/10.1017/CBO9781107415324.004

Butt, G., \& Lance, A. (2005). Secondary Teacher Workload and Job Satisfaction: Do Successful Strategies for Change Exist? Educational Management Administration \& Leadership. https://doi.org/10.1177/1741143205056304

Byrne, D. (2013). Complexity Theory and the Social Sciences. Complexity Theory and the Social Sciences. https://doi.org/10.4324/9780203519585

Chan, A. H. S., Chen, K., \& Chong, E. Y. L. (2010). Work stress of teachers from primary and secondary schools in Hong Kong. In Proceedings of the International MultiConference of Engineers and Computer Scientists 2010, IMECS 2010.

Chin, W. W. (1998). The partial least squares approach for structural equation modeling. In GA Marcoulides (ed.),

Modern Methods for Business Research, 295-336.Lawrence Erlbaum Associates, London.

Cohen, J. (1988). Statistical power analysis for the behavioral sciences (2nd ed.). Hillsdale, NJ: Lawrence Earlbaum Associates. Dunlop, W. P., Cortina, J. M., Vaslow, J. B., \& Burke, M. J. (1996). Meta-analysis

Davidson, K. (2009). Challenges contributing to teacher stress and burnout. Southeastern Teacher Education Journal.

De Simone, S., Cicotto, G., \& Lampis, J. (2016). Occupational stress, job satisfaction and physical health in teachers. Revue Europeenne de Psychologie Appliquee, 66(2), 65-77. https://doi.org/10.1016/j.erap.2016.03.002

Fisher, M. H. (2011). Factors Influencing Stress, Burnout, and Retention of Secondary Teachers. Current Issues in Education, 14, 1-36. 
Fornell, C. and Cha, J. (1994) Partial Least Squares. Advanced Methods of Marketing Research, 407, $52-78$

Fornell, C., \& Larcker, D. (1981).Evaluating structural equation models with unobservable variables and measurement error.Journal of Marketing Research, 18(1), 39-50.

Gladys De Rozario \& Muhamad Suhaimi Taat. 2015. The Influence of Learning Environment And Academic SelfEfficacy Towards Mathematics Achievement In Masterskill Global College, Malaysia. International Journal of Arts And Commerce. 1. 43-53.

Greenberg, M. T., Brown, J. L., \& Abenavoli, R. M. (2016). Teacher stress and health: Effects on teachers, students, and schools. Edna Bennett Pierce Prevention Research Center, The Pennsylvania State University.

Geving, A. M. 2007. Identifying the types of student and teacher behaviours associated with teacher stress. Teaching and Teacher Education. https://doi.org/10.1016/j.tate.2007.02.006

Hair, J. F., Hult, G. T. M. Ringle, C. M., \& Sarstedt, M. (2014). A primer on partial least squares structural equation modeling Thousand Oaks: Sage.

Hair, J. F., Hult, G. T. M. Ringle, C. M., \& Sarstedt, M. (2017). A primer on partial least squares structural equation modeling. 2nd Edition. Thousand Oaks: Sage.

Hopkins, M. L. (2014). The sources of work stress and coping resources for high school teachers in the Gauteng Province within different career stages (Doctoral dissertation).

Hakanen, J. J., Bakker, A. B., \& Schaufeli, W. B. (2006). Burnout and work engagement among teachers. Journal of School Psychology. https://doi.org/10.1016/j.jsp.2005.11.001

Ismail, O. C. H. A. (2015). Sokongan Pihak Pengurusan Sekolah terhadap Tekanan Kerja Guru di Sekolah Kebangsaan dan Sekolah Jenis Kebangsaan Cina. Jurnal Kepimpinan Pendidikan.

Jaggil Apak \& Muhamad Suhaimi Taat. 2018. Pengaruh Kesediaan Guru Terhadap Pengurusan Bilik Darjah Abad Ke-21. Malaysian Journal of Social Sciences and Humanities (MJ - SSH). 3(4), 622.

Kamaruddin, K. (2007). Tekanan Kerja di kalangan guru sekolah menengah. Jurnal Kemanusiaan, $10(1), 105-118$.

Karaj, S. Rapti, E. (2013). Teacher stress in Albania: examining the role of students' classroom deviant behavior and other factors in the school context. Problems of Education in the 21st Century, 54(54), 14-21. Retrieved from http://www.scientiasocialis.lt/pec/files/pdf/vol54/1421.Karaj_Vol.54.pdf

Kaur, S. (2011). Comparative Study of Occupational Stress among Teachers of Private and Govt. Schools in Relation to their Age, Gender and Teaching Experience. International Journal of Educational Planning \& Administration. https://doi.org/10.1177/1362361307078130

Kerr, R. A., Kerr, R. A., Breen, J., Delaney, M., Kelly, C., \& Miller, K. (2011). A Qualitative Study of Workplace Stress and Coping in Secondary Teachers in Ireland. Irish Journal of Applies Social Studies. https://doi.org/10.21427/D7G72Q

Kidger, J., Brockman, R., Tilling, K., Campbell, R., Ford, T., Araya, R., ... Gunnell, D. (2016). Teachers' wellbeing and depressive symptoms, and associated risk factors: A large cross sectional study in English secondary schools. Journal of Affective Disorders. https://doi.org/10.1016/j.jad.2015.11.054

Kokoroko, E., \& Sanda, M. A. (2019). Effect of Workload on Job Stress of Ghanaian OPD Nurses: The Role of Coworker Support. Safety and Health at Work. https://doi.org/10.1016/j.shaw.2019.04.002

Kyriacou, C. (2001). Teacher stress: Directions for future research. Educational Review. https://doi.org/10.1080/00131910120033628

Mathew, L. (2011). An Exploratory Study on Occupational Stress and Coping Strategies of Special Educators in South India. SSRN Electronic Journal. https://doi.org/10.2139/ssrn.643192

Mohamad Abdillah Royo \& Woo Sew Fun (2008). Faktor-Faktor Yang Mendorong Tekanan Kerja (Stres) Di Kalangan Guru-Guru Sjk(C): Satu Kajian Di Tiga Buah Sekolah Di Wilayah Persekutuan. Fakulti Pendidikan, Universiti Teknologi Malaysia.

Mohamed T. (2018) Sources of Occupational Stress Among Teachers: A Field of Study for Teachers Working in Libyan Schools in Turkey International Journal of Academic Research in Economics and Management Sciences

http://dx.doi.org/10.6007/IJAREMS/v7i8

Mohd Arshad, Z, \& Mustapha, R. (2017). Hubungan Antara Beban Tugas Dengan Efikasi Diri dan 
DOI: https://doi.org/10.47405/mjssh.v5i11.544

Kepuasan Kerja Pensyarah di Kolej Vokasional. Sains Humanika, 9(1-5). https://doi.org/10.11113/sh.v9n1-5.1174

Muhamad Suhaimi Taat \& Gladys De Rozario. 2014. The Influence of Academic Attitude and SelfEfficacy Towards Students Achievement in Private Higher Learning Institution, Malaysia. International Journal of Arts and Commerce. 1, 41-50.

Ngui G.K; Lay Y.F. (2015). Relationship between Stress Coping Factors with Stress Level during Practical Training among Trainee Teachers: A PLS-SEM Approach. Prosceeding ICE Brunei 2015.

Onditi, A. a. (2013). Relationship between customer personality, service features and customer loyalty in the banking sector: A survey of banks in homabay county, Kenya. International Journal of Business and Social Science.

Ouellette, R. R., Frazier, S. L., Shernoff, E. S., Cappella, E., Mehta, T. G., Marínez-Lora, A. Atkins, M. S. (2018). Teacher Job Stress and Satisfaction in Urban Schools: Disentangling Individual-, Classroom-, and Organizational-Level Influences. Behavior Therapy, 49(4), 494-508. https://doi.org/10.1016/j.beth.2017.11.011

Robbins, S., De Cenzo, D., Coulter, M., \& Woods, M. (2013). Management: the essentials. Pearson Higher Education AU.

Samad, N. I. A., Hashim, Z., Moin, S., \& Abdullah, H. (2011). Assessment of Stress and Its Risk Factors Among Primary School Teachers in the Klang Valley, Malaysia. Epidemiology. https://doi.org/10.1097/01.ede.0000392452.76957.b9

Sanyal, N., Fernandes, T., \& Fatima, A. (2016). Personal Effectiveness, Organizational Culture and Work-Related Stress among Teachers. IRA International Journal of Education and Multidisciplinary Studies (ISSN 2455-2526). https://doi.org/10.21013/jems.v4.n2.p4

Shkembi, F., Melonashi, E., \& Fanaj, N. (2015). Workplace Stress Among Teachers in Kosovo. SAGE Open. https://doi.org/10.1177/2158244015614610

Tajulashikin, J., Fazura, M. N., \& Ibrahim, M. B. (2013). Faktor-Faktor Penentu Stres Dalam Kalangan Guru: Sekolah Rendah Mubaligh Di Kuala Lumpur. Jurnal Kurikulum \& Pengajaran Asia Pasifik. https://doi.org/10.1016/j.larev.2016.06.007

Van Bogaert, P., Timmermans, O., Weeks, S. M., van Heusden, D., Wouters, K., \& Franck, E. (2014). Nursing unit teams matter: Impact of unit-level nurse practice environment, nurse work characteristics, and burnout on nurse reported job outcomes, and quality of care, and patient adverse events-A cross-sectional survey. International Journal of Nursing Studies. https://doi.org/10.1016/j.ijnurstu.2013.12.009

Yaribeygi, H., Panahi, Y., Sahraei, H., Johnston, T. P., \& Sahebkar, A. (2017). The impact of stress on body function: A review. EXCLI Journal. https://doi.org/10.17179/excli2017-480 